\title{
Antibiotic Resistance of Some Lactobacilli Isolated from the Digestive Tract of Broiler in Western Algeria
}

\author{
${ }^{1}$ Behira Belkacem and ${ }^{2}$ Kihal Mebrouk \\ ${ }^{1}$ Faculty of Sciences, Mascara University, Algeria \\ ${ }^{2}$ Department of Microbiology, Faculty of Sciences, Senia University, Oran, Algeria
}

\begin{abstract}
The lactobacilli of the digestive tract poultry are considered as a reservoir of genes for resistance to antibiotics. Lactobacilli colonizing the crop and intestines of broilers play an important role in maintaining the balance of the health of the animal. The current trend that aims to spread the use of lactobacilli as a probiotic in poultry is confronted by abuse as curative despite regulations and guidelines that prohibit the routine use of antibiotics for the treatment of microbial infections poultry. The study is conducted on the lactobacilli flora of broiler chickens in Western Algeria. Ten isolates from the crop and intestines broiler. Antimicrobial sensitivity test to ten different types of antibiotic were evaluated using the disc diffusion method. Inhibition zone diameter was measured of resistance or susceptibility.
\end{abstract}

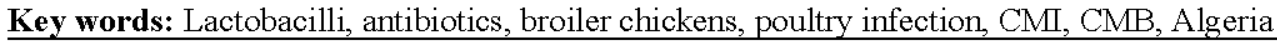

\section{INTRODUCTION}

About 50 years ago, antibiotics were introduced for the treatment of microbial diseases. Since then, the greatest threat to the use of antimicrobial agents for therapy of bacterial infections has been the development of antimicrobial resistance in pathogenic bacteria (Mathur and Singh, 2005). Acquired antibiotic resistance, i.e., resistance genes located on conjugative or mobilizable plasmids and transposons can be found in species living in habitats (e.g., human and Lactic acid bacteria) may act as reservoirs of antibiotic resistance genes that can be transferred via the food chain or within the gastrointestinal tract to pathogenic bacteria (Egervarn, 2009). The gastrointestinal tract microflora of poultry is a mixture of bacteria, fungi and protozoa but bacteria are the predominant microorganisms.

Several mechanisms of antimicrobial resistance are readily spread to a variety of bacterial genera. First, the organism may acquire genes encoding enzymes such as lactamases that destroy the antibacterial agent before it can have an effect. Second, bacteria may acquire efflux pumps that extrude the antibacterial agent from the cell before it can reach its target site and exert its effect.

Third, bacteria may acquire several genes for a metabolic pathway which ultimately produces altered bacterial cell walls that no longer contain the binding site of the antimicrobial agent or bacteria may acquire mutations that limit access of antimicrobial agents to the intracellular target site via down regulation of porin genes
(Tenover, 2006). Lactic acid bacteria may act as reservoirs of antibiotic resistance genes that can be transferred via the food chain or within the gastrointestinal tract to pathogenic bacteria (Egervarn, 2009).

The gastrointestinal tract microflora of poultry is a mixture of bacteria, fungi and protozoa but bacteria are the predominant microorganisms. Broiler chicken diets containing corn, sorghum, barley, oats or rye had various effects as corn- and sorghum-based diets increased numbers of Enterococcus, barley-based diet increased numbers of Lactobacillus, oats-based diet enhanced growth of Escherichia and Lactococcus and rye-based diet increased the number of Streptococcus in broiler chickens.

In poultry farming as well as with other intensively reared animals, antibiotics may be administered, though feed or drinking water to whole focks rather than to individual animals. In the European Community $(\mathrm{EC})$, the water or feed-based administration of antimicrobials to animals (at lower doses than those employed for therapeutic purposes) to enhance animal growth has been completely banned since, January 2006.

The microflora of the crop consists of large numbers of lactobacilli and smaller numbers of coliforms and streptococci. The lactobacilli remain dominant throughout the small intestine. It is only in the caeca where different nutritional conditions exist and residence time is longer that the strict anaerobes become the dominant components of the microflora (Fuller, 2001). A key requirement for probiotic strains is that they should not

Corresponding Author: Behira Belkacem, Faculty of Sciences, Mascara University, Algeria 
carry transmissible antibiotic resistance genes. Ingestion of bacteria carrying such genes is undesirable as horizontal gene transfer to recipient bacteria in the gut could lead to the development of new antibiotic-resistant pathogens (Zhou et al., 2005).

\section{MATERIALS AND METHODS}

Bacterial cultures and growth conditions: The ten Lactic Acid Bacteria strains (LAB) in this study (Table 1) had been previously isolated from crop and intestine of broiler. The contents were suspended in MRS broth and incubated at $37^{\circ} \mathrm{C}$ for $18 \mathrm{~h}$. After incubation, colonies were examined on the basis of different morphologies. All types of colonies were examined for catalase activity and were microscopically examined after gram stain. Only the catalase negative colonies were picked up and cultured in MRS broth after incubation for $18 \mathrm{~h}$ at $37^{\circ} \mathrm{C}$, cells were harvested by centrifugation $(5000 \mathrm{~g} / 10 \mathrm{~min})$ and washed twice in sterile physiological water $0.9 \% \mathrm{NaCl}$. The washed cells were resuspended and diluted in physiological water $0.9 \% \mathrm{NaCl}$ to form standard inoculum with an optical density at $600 \mathrm{~nm}\left(O D_{600}\right)$ of 0.1 $\left(10^{8} \mathrm{cfu} \mathrm{mL}^{-1}\right)$.

Antibiotic susceptibility testing: Ten bacterial isolates were screened for antibiotic susceptibility. The Disc diffusion method was used according to the NCCLS instructions slightly modified and tested against ten antibiotics including: $\beta$-lactams group; penicillin $\mathrm{G}(6 \mu \mathrm{g})$, ampicillin $(10 \mu \mathrm{g})$ and amoxycillin $(30 \mu \mathrm{g})$. Macrolide group: erytromycin $(15 \mu \mathrm{g})$, spiramycin $(100 \mu \mathrm{g})$, clindomycin $(2 \mu \mathrm{g})$, lincomycin $(15 \mu \mathrm{g})$. Aminosids group: gentamicin $(10 \mu \mathrm{g})$, naxilidic acid $(30 \mu \mathrm{g})$ fusidic acid $(10 \mu \mathrm{g})$. The disks were placed on the agar surface and the plates were incubated anaerobically for $18 \mathrm{~h}$. Resistance was defined no zone of growth inhibition around the disk. All incubations were at $37^{\circ} \mathrm{C}$. The discs were verified by $E$. coli ATCC 25922 reference strain as quality control. Resistance and susceptibility were evaluated according to CASFM. In the 2nd part of the study, four antibiotics obtained from commercial sources, i.e., penicillin $\mathrm{G}$, amoxicillin, ampicillin and gentamicin were determined using the reference Agar-dilution method recommended by the CA-SFM were used for the determination the $\mathrm{MIC}$ and $\mathrm{MBC}$ of some highly resistant strains. The final concentration ranges were $20,40,60,80$ and $100 \mu \mathrm{g} \mathrm{mL}{ }^{-1}$.

The MICs were determined by microdilution method. The microtiter plates were incubated for 18 to $24 \mathrm{~h}$ at $37^{\circ} \mathrm{C}$ with a source of moisture to prevent dehydration. The $\mathrm{MIC}$ was determined by visual observation of the lowest concentration that yielded no visible growth. The MIC was defined as the concentration of the antibiotic that elicited approximately $80 \%$ inhibition of growth. MBCs were determined by subculturing $0.1 \mathrm{~mL}$ aliquots from each tube onto MRS agar plates. Plates were incubated at $37^{\circ} \mathrm{C}$ for $48 \mathrm{~h}$ in anaerobiosis. The $\mathrm{MBC}$ was defined as the lowest antibiotic concentration yielding five or less visible colonies on agar.

\section{RESULTS AND DISCUSSION}

The isolates were gram positive and all were homofermentaire, catalase negative, grew at $45^{\circ} \mathrm{C}$, produce $\mathrm{NH}_{3}$ from arginine, resist to $63^{\circ} \mathrm{C}$ for $30 \mathrm{~min}$. The carbohydrate fermentation profiles of the isolates (Table 1) were affected according to Hammes and Hertel (2006). These results are similar with the results found by Abbas Hilmi et al. (2007). According this researcher, nearly $98 \%$ of the sequences belonged to the genus Lactobacillus and the three most abundant Lactobacillus species detected in the crop samples were Lactobacillus reuteri (33\%), Lactobacillus crispatus (18.7\%) and Lactobacillus salivarius (13.3\%). In similar study, Lu et al. (2003) were found that the lactobacillus genera form $98 \%$ of the microbiota of ileum. The strain Lactobacillus salivarius LC1 is resistant to all antibiotics

Table 1: Carbohy drates fermented of isolated strains

\begin{tabular}{|c|c|c|c|c|c|c|c|c|c|c|c|}
\hline \multirow[b]{2}{*}{ Isolates } & \multicolumn{11}{|c|}{ Carbohydrates } \\
\hline & Galactose & Lactose & Maltose & Mannose & Mannitol & Raffinose & Salicin & Sucrose & Trehalose & Melibiose & Cellibiose \\
\hline$\overline{\mathrm{LbC} 1}$ & + & + & + & - & + & + & - & + & + & + & - \\
\hline $\mathrm{LbC} 2$ & + & + & + & + & - & + & + & + & + & + & + \\
\hline $\mathrm{LbC} 3$ & + & + & + & + & - & + & + & + & - & + & + \\
\hline $\mathrm{LbC} 4$ & + & + & + & + & - & - & + & + & - & - & + \\
\hline LbC5 & - & - & + & + & - & + & + & + & + & - & + \\
\hline LbI 1 & + & + & + & + & - & - & + & + & - & - & + \\
\hline LbI 2 & + & + & + & - & + & + & - & + & + & + & - \\
\hline LbI 3 & + & + & + & + & - & + & + & + & + & + & + \\
\hline LbI 4 & + & + & + & + & - & + & + & + & - & + & + \\
\hline$\underline{\text { LbI } 5}$ & + & + & + & + & - & - & + & + & - & - & + \\
\hline
\end{tabular}


tested but susceptible to amoxicillin, lincomycin and fusidic acid. Lactobacillus jonshonii LC2 is susceptible to penicillin, amoxicillin and clindomycin and resistant to the others antibiotics. Lactobacillus gallinarum LC3 is resistant to all antibiotics tested except Clindomycin and fusidic acid. Lactobacillus crispatus LC4 is susceptible both to amoxicillin and spiramycin. Lactobacillus aviarus LC5 is resistant to all antibiotics tested (Table 2 and 3 ).

The isolates from intestines were resistant to all antibiotics except Lactobacillus gallinarum LI4 was susceptible to ampicillin and Lactobacillus crispatus LI5 was susceptible to erythromycin. The isolates from intestines as indeginious microflora are most resistant than the isolates crop because their exposition and adaptation for long time to antibiotics. All the isolates were resistant to naxilidic acid.

Hummel et al. (2007) reported that lactobacilli seem to be intrinsically resistant to quinolones, e.g., ciprofloxacin and nalidixic acid by a currently unknown resistance mechanism. Lactobacillus salivarius LC1 and Lactobacillus gallinarum LC3 were showed susceptibility to fusidic acid. Zhou et al. (2005) reported that many strains of lactobacilli were resistant to gramnegative spectrum antibiotics (fusidic acid, nalidixic acid and polymyxin B) and aminoglycosides (gentamicin, kanamycin, neomycin and streptomycin). All the isolates were resistant to penicillin. Generally lactobacilli seem to be sensitive to penicillins (Danielsen and Wind, 2003). Also, Danielsen and Wind (2003) were reported that some lactobacilli have a high natural resistance to bacitracin, cefoxitin, ciprofloxacin, kanamycin, gentamicin, metronidazole, nitrofurantoin, norfloxacin, streptomycin, sulphadiazine, teicoplanin and vancomyci.

All the isolates were resistant to gentamicin. Similary, Pulido et al. (2005) found that some isolates of lactobacilli were inhibited by gentamicin. Toomey were found that resistance among lactobacilli isolates appeared to vary between species.

Most of the observed resistances seemed to be intrinsic but some others could be compatible with transmissible determinants (Delgado et al., 2005). Although, lactobacilli are generally susceptible to antibiotics that inhibit the synthesis of protein such as erythromycin and tetracycline (Ammor et al., 2007; Essid et al., 2009), we have found that all strains were resistant to erythromycin except Lactobacillus crispatus (LI5).

The determination of MICs shows that the all strains tested have an acquired resistance (Table 4). Knowledge of the distributions of antibiotic Minimum Inhibitory Concentrations (MICs) for species is needed when using a phenotypic method to differentiate strains with acquired resistance from susceptible strains or strains with intrinsic resistance (Egervarn, 2009). For ampicillin MICs of $20-80 \mu \mathrm{g} \mathrm{mL} \mathrm{m}^{-1}$ for amoxicillin MICs of $40-60 \mu \mathrm{g} \mathrm{mL}^{-1}$ for penicillin MCs of $20-40 \mu \mathrm{g} \mathrm{mL}^{-1}$ were obtained (Table 4). This is in contrast to the common opinion of lactobacilli being susceptible to penicillins

Table 2: Measure of diameter inhibition zone (mm) of each isolate

\begin{tabular}{|c|c|c|c|c|c|c|c|c|c|c|}
\hline \multirow[b]{2}{*}{ Antibiotics } & \multicolumn{10}{|c|}{ Strains } \\
\hline & $\mathrm{LbC1}$ & $\mathrm{LbC} 2$ & $\mathrm{LbC3}$ & $\mathrm{LbC4}$ & LbC5 & LbI1 & $\mathrm{LbI} 2$ & LbI3 & $\mathrm{LbaI} 4$ & LbI5 \\
\hline Erythromy cin & 11 & 10 & 12 & 0 & 0 & 10 & 10 & 9 & 0 & 25 \\
\hline Gentamicin & 10 & 9 & 0 & 0 & 0 & 8 & 8 & 0 & 0 & 0 \\
\hline Penicillin & 12 & 18 & 0 & 16 & 0 & 12 & 12 & 0 & 16 & 10 \\
\hline Amoxicillin & 25 & 30 & 10 & 20 & 0 & 15 & 0 & 15 & 0 & 10 \\
\hline Lincomy cin & 20 & 8 & 0 & 0 & 0 & 0 & 8 & 0 & 10 & 10 \\
\hline Ampicillin & 0 & 14 & 0 & 10 & 9 & 10 & 8 & 0 & 20 & 0 \\
\hline Spiramy cin & 10 & 10 & 0 & 20 & 0 & 0 & 12 & 0 & 17 & 9 \\
\hline Clindomycin & 0 & 19 & 20 & 0 & 0 & 8 & 9 & 12 & 0 & 14 \\
\hline Naxilidic acid & 0 & 0 & 0 & 0 & 7 & 0 & 0 & 0 & 0 & 0 \\
\hline Fusidic acid & 21 & 12 & 30 & 0 & 0 & 0 & 12 & 0 & 17 & 9 \\
\hline
\end{tabular}

Table 3: antibiotic susceptibility profiles of test strains

\begin{tabular}{|c|c|c|c|c|c|c|c|c|c|c|}
\hline \multirow[b]{2}{*}{ Antibiotics } & \multicolumn{5}{|c|}{ Isolates from crops } & \multicolumn{5}{|c|}{ Isolates from intestines } \\
\hline & $\mathrm{LbC1}$ & $\mathrm{LbC} 2$ & $\mathrm{LbC3}$ & $\mathrm{LbC4}$ & LbC5 & LbI1 & $\mathrm{LbI} 2$ & $\mathrm{LbI} 3$ & $\mathrm{LbI} 4$ & LbI5 \\
\hline Erythromy cin & $\mathrm{R}$ & $\mathrm{R}$ & $\mathrm{R}$ & $\mathrm{R}$ & $\mathrm{R}$ & $\mathrm{R}$ & $\mathrm{R}$ & $\mathrm{R}$ & $\mathrm{R}$ & $\mathrm{S}$ \\
\hline Gentamicin & $\mathrm{R}$ & $\mathrm{R}$ & $\mathrm{R}$ & $\mathrm{R}$ & $\mathrm{R}$ & $\mathrm{R}$ & $\mathrm{R}$ & $\mathrm{R}$ & $\mathrm{R}$ & $\mathrm{R}$ \\
\hline Penicillin & $\mathrm{R}$ & $\mathrm{R}$ & $\mathrm{R}$ & $\mathrm{R}$ & $\mathrm{R}$ & $\mathrm{R}$ & $\mathrm{R}$ & $\mathrm{R}$ & $\mathrm{R}$ & $\mathrm{R}$ \\
\hline Amoxicillin & $S$ & $\mathrm{~S}$ & $\mathrm{R}$ & $\mathrm{S}$ & $\mathrm{R}$ & $\mathrm{R}$ & $\mathrm{R}$ & $\mathrm{R}$ & $\mathrm{R}$ & $\mathrm{R}$ \\
\hline Lincony cin & $\mathrm{S}$ & $\mathrm{R}$ & $\mathrm{R}$ & $\mathrm{R}$ & $\mathrm{R}$ & $\mathrm{R}$ & $\mathrm{R}$ & $\mathrm{R}$ & $\mathrm{R}$ & $\mathrm{R}$ \\
\hline Ampicillin & $\mathrm{R}$ & $\mathrm{R}$ & $\mathrm{R}$ & $\mathrm{R}$ & $\mathrm{R}$ & $\mathrm{R}$ & $\mathrm{R}$ & $\mathrm{R}$ & $\mathrm{S}$ & $\mathrm{R}$ \\
\hline Spiramy cin & $\mathrm{R}$ & $\mathrm{R}$ & $\mathrm{R}$ & $\mathrm{S}$ & $\mathrm{R}$ & $\mathrm{R}$ & $\mathrm{R}$ & $\mathrm{R}$ & $\mathrm{R}$ & $\mathrm{R}$ \\
\hline Clindomycin & $\mathrm{R}$ & $\mathrm{S}$ & $\mathrm{S}$ & $\mathrm{R}$ & $\mathrm{R}$ & $\mathrm{R}$ & $\mathrm{R}$ & $\mathrm{R}$ & $\mathrm{R}$ & $\mathrm{R}$ \\
\hline Naxilidic acid & $\mathrm{R}$ & $\mathrm{R}$ & $\mathrm{R}$ & $\mathrm{R}$ & $\mathrm{R}$ & $\mathrm{R}$ & $\mathrm{R}$ & $\mathrm{R}$ & $\mathrm{R}$ & $\mathrm{R}$ \\
\hline Fusidic acid & $\mathrm{S}$ & $\mathrm{R}$ & $\mathrm{S}$ & $\mathrm{R}$ & $\mathrm{R}$ & $\mathrm{R}$ & $\mathrm{R}$ & $\mathrm{R}$ & $\mathrm{R}$ & $\mathrm{R}$ \\
\hline
\end{tabular}


Table 4: Determination of CMIs $\left(\mu \mathrm{g} \mathrm{mL}^{-1}\right)$ and CMBs $\left(\mu \mathrm{g} \mathrm{mL}^{-1}\right)$ of some

\begin{tabular}{llcr}
\multicolumn{2}{c}{ inherent isolates } & & \\
\hline Antibiotics & Isolates & CMI & CMB \\
\hline Gentamicin & LbC3 & 40 & 80 \\
& LbC4 & 40 & 80 \\
& LbC5 & 60 & 100 \\
& LbI 3 & 60 & 80 \\
& LbI 4 & 40 & 80 \\
Amoxicillin & LbI 5 & 40 & 60 \\
& LbC5 & 60 & 100 \\
& LbI2 & 40 & 80 \\
Ampicillin & LbI4 & 40 & 60 \\
& LbC1 & 60 & 80 \\
& LbC3 & 60 & 80 \\
& LbI3 & 20 & 40 \\
Penicillin G & LbI5 & 80 & 100 \\
& LbC3 & 20 & 60 \\
\hline
\end{tabular}

in general (Danielsen and Wind, 2003; Hummel et al., 2007). Finally, antibiotics resistance of lactobacillus could also be regarded as a beneficial property. A resistant probiotic strain that is co-administered with an antibiotic may reduce the gastrointestinal side effects related to antibiotic treatment (Courvalin, 2006). By identifying strains with potentially non-transferable resistance genes, this field of application might gain wider acceptance and thus have a greater impact in the future.

\section{CONCLUSION}

All the isolates were resistant to Spiramycin and Gentamicin. Except one isolate is susceptible to Erythromycin; tree are susceptible to Amoxicilline; one to Ampicilin; one to Penicillin G and one to Clindomycin. The Minimum Inhibitory Concentration (CMI) and the Concentration Minimum Bactericide (CMB) were evaluated for each strain resistant toward the most antibiotics employed for therapeutic purposes in broiler chickens in West Algeria.

\section{REFERENCES}

Abbas Hilmi, H.T., A. Surakka, J. Apajalahti, and P.E. Saris, 2007. Identification of the most abundant Lactobacillus species in the crop of 1- and 5-weekold broiler chickens. Appl. Environ. Microbiol., 73: 7867-7873.

Ammor, M.S., A.B. Florez and B. Mayo, 2007. Antibiotic resistance in non-enterococcal lactic acid bacteria and bifidobacteria. Food Microbiol., 24: 559-570.
Courvalin, P., 2006. Antibiotic resistance: The pros and cons of probiotics. Digestive Liver Dis., 38: S261-S265.

Danielsen, M. and A. Wind, 2003. Susceptibility of Lactobacillus spp. to antimicrobial agents. Int. J. Food Microbiol., 82: 1-11.

Delgado, S., A.B. Florez and B. Mayo, 2005. Antibiotic susceptibility of Lactobacillus and Bifidobacterium species from the human gastrointestinal tract. Curr. Microbiol., 50: 202-207.

Egervarn, M., 2009. Antibiotic resistance in Lactobacillus reuteri and Lactobacillus plantarum. Doctoral Thesis, Swedish University of Agricultural Sciences Uppsala.

Essid, I., M. Medini and M. Hassouna, 2009. Technological and safety properties of Lactobacillus plantarum strains isolated from a Tunisian traditional salted meat. Meat Sci., 81: 203-208.

Fuller, R., 2001. The chicken gut microflora and probiotic supplements. J. Poult. Sci., 38: 189-196.

Hammes, W. and C. Hertel, 2006. The genera Lactobacillus and Carnobacterium. Procaryotes, 4: $320-403$.

Hummel, A.S., C. Hertel, W.H. Holzapfel and C.M.A.P. Franz, 2007. Antibiotic resistances of starter and probiotic strains of lactic acid bacteria. Applied Environ. Microb., 73: 730-739.

Lu, J., U. Idris, B. Harmon, C. Hofacre, J.J. Maurer and M.D. Lee, 2003. Diversity and succession of the intestinal bacterial community of the maturing broiler chicken. Applied Environ. Microbiol., 69: 6816-6824.

Mathur, S. and R. Singh, 2005. Antibiotic resistance in food lactic acid bacteria-A review. Int. J. Food Microbiol., 105: 281-295.

Pulido, R.P., N.B. Omar, R. Lucas, H. Abriouel, M.M. Canamero and A. Galvez, 2005. Resistance to antimicrobial agents in lactobacilli isolated from caper fermentations. Antonie Leeuwenhoek, 88: 277-281.

Tenover, F.C., 2006. Mechanisms of antimicrobial resistance in bacteria. Am. J. Med., 119: S3-S10.

Zhou, J.S., C.J. Pillidge, P.K. Gopal and H.S. Gill, 2005. Antibiotic susceptibility profiles of new probiotic Lactobacillus and Bifidobacterium strains. Int. J. Food Microbiol., 98: 211-217. 